\title{
PENERAPAN SANKSI TERHADAP PENGGUNA KNALPOT NON-STANDAR DI JALAN RAYA
}

\author{
R. Adi Nurzaman, Budi Arta Atmaja, Ajie Ramdan \\ Fakultas Hukum, Universitas Padjadjaran \\ E-mail: adi.nurzaman@unpad.ac.id
}

\begin{abstract}
ABSTRAK. Kendaraan sepeda motor sangat sering digunakan oleh masyarakat karena fleksibilitasnya sehingga dapat membantu aktivitas dan rutinitas sehari-hari. Semakin berkembangnya zaman semakin banyak inovasi-inovasi yang muncul untuk memberikan rasa nyaman dalam berkendara. Hal ini menyebabkan berbagai variasi spesifikasi komponen, diantaranya adalah variasi knalpot motor. Variasi knalpot motor seringkali disalahgunakan oleh pengguna dimana knalpot yang digunakan menimbulkan suara yang bising yang dapat mengganggu kenyamanan masyarakat. Pemerintah telah menetapkan Undang-Undang yang mengatur hal ini, yaitu Undang-Undang Nomor 22 Tahun 2009 tentang Lalu Lintas dan Angkutan jalan. Selain itu, Peraturan Menteri Lingkungan Hidup No. 7 Tahun 2009 tentang Ambang Batas Kebisingan Kendaraan Bermotor Tipe Baru mengatur batas maksimum kebisingan kendaraan bermotor. Dalam Pelaksanaan penegakan hukum masih kurang efektif dikarenakan penegak hukum tidak membawa alat suara di lapangan sehingga penetapan pelanggaran hanya berdasarkan intuisi penegak hukum. Banyaknya pelanggar juga akibat kurangnya pemahaman masyarakat terhadap tingkat kebisingan yang diperbolehkan oleh penegak hukum.
\end{abstract}

Kata kunci: Kendaraan Roda Dua; Knalpot; Sanksi

ABSTRACT. Motorcycle vehicles are very often used by the community because of their flexibility so they can helm with daily activities and routines. The growing age of more and more innovations that appear to provide comfort in driving. This causes various variations in component specifications, including variations in motorbike exhaust. Variations in motorbike exhaust are often misused by users where the exhaust used causes noises that can disturb people's comfort. The Government has enacted a law which regulates this matter, namely "Undang-Undang Nomor 22 Tahun 2009" concerning Road Traffic and Transportation. In addition, namely "Peraturan Menteri Lingkungan Hidup No.7 Tahun 2009" concerning The New Type Motorized Noise Threshold regulates the maximum limit of motorized vehicle noise. In the implementation of law enforcement it is still not effective because law enforcers do not carry sound equipment in the field so that the determination of violations is only based on the intuition of law enforcement. The number of violators is also due to a lack of public understanding of the noise levels allowed by law enforcement.

Key words: Two-Wheeled Vehicle; Exhaust; Punishment

\section{PENDAHULUAN}

Pada saat ini penggunaan kendaraan sepeda motor semakin meningkat. Kebutuhan akan alat transportasi ini menjadi sangat penting karena kepraktisannya sehingga menjadi tumpuan untuk melakukan aktivitas sehari-hari. Menurut data Dinas Perhubungan Kota Bandung, sampai dengan 19 Maret2018kendaraan roda dua di KotaBandung sebanyak 1.251.080 unit (Badan Pusat Statistik Provinsi Jawa Barat, 2018), yang mana mengalami peningkatan rata-rata $11 \%$ setiap tahunnya (Dea Andriyawan, 2018). Hal yang dicari oleh pengguna jalan adalah kenyamanan dalam berkendara, tak jarang dan bahkan banyak dari pengendara roda dua yang memodifikasi sepeda motornya dengan cara merubah spesifikasi komponen ataupun dengan cara memberi komponen tambahan pada kendaraannya (IPTU Rustandi, 2018). Hal ini yang mengakibatkan maraknya berbagai macam variasi untuk kendaraan roda dua untuk dapat memuaskan hasrat modifikasi dari para pemilik kendaraan roda dua tersebut, contohnya adalah penggantian knalpot motor. Hal ini bisa dilihat dari hasil dokumentasi penindakan pengguna knalpot non-standar yang dilakukan oleh anggota Sat lantas Polrestabes Kota Bandung,

Penggantian knalpot motor seringkali disalah gunakan oleh pengguna, dimana knalpot yang digunakan menimbulkan suara bising yang dapat mengganggu kenyamanan masyarakat. Menindaklanjuti hal tersebut pemerintah menetapkan Undang-Undang yang mengatur hal ini, yaitu Undang-Undang Nomor 22 Tahun 2009 tentang Lalu Lintas dan Angkutan jalan. Isi dari peraturan perundang-undangan tersebut sangat bersentuhan dengan masyarakat, dimana terdapat kebijakan-kebijakan baru yang sebelumnya belum ada di undang-undang yang lama yaitu Undang-Undang Nomor 14 Tahun 1992 tentang lalu lintas dan angkutan jalan.

Dampak yang ditimbulkan dari pelanggaran sepeda motor khususnya penggunaan knalpot non-standar dianggap cukup merugikan bagi pengguna jalan lain, adapun dampak yang ditimbulkan yaitu berupa kebisingan suara, polusi udara, bisa memicu aksi kebut-kebutan di jalan raya hingga timbulnya kecelakan yang dapat menghilangkan nyawa sebanyak 363 orang (Polda Jawa Barat, 2020). Tingkat pemahaman para pengendara yang rendah terhadap dampak yang dapat terjadi menjadi salah satu indikator bahwa masih banyaknya pengguna knalpot non standar. Adanya pemakluman atau bahkan penolakan terhadap penggunaan knalpot non standar merupakan implementasi dari tingkat pemahaman tersebut.

\section{METODE}

Metode yang digunakan dalam Kuliah Kerja Nyata Terintegrasi program Pengabdian Pada Masyarakat (KKN- 
PPM) ini yaitu penelitian hukum normatif dan bersifat deskriptif analitis. Penelitian hukum normatif bertujuan untuk menemukan hukum in concreto, yang merupakan usaha untuk menemukan apakah hukumnya sesuai untuk diterapkan atau tidak dalam menyelesaikan suatu perkara tertentu dan dimanakah bunyi peraturan hukum itu dapat ditemukan (Ronny Hanitijo Soemitro,1988). Dalam menegakan hukum ada tiga unsur yang harus diperhatikan yaitu Kepastian Hukum (rechtssicherheit), Manfaat (zweckmassigkeit), Keadilan (gerechtigkeit) (Sudikno Mertokusumo, 1999). Deskriptif analitis digunakan untuk menggambarkan dan menganalisa data primer, sekunder, dan tersier. Di dalam penelitian ini akan dikemukakan gambaran terkait dengan permasalahan penelitian, perangkat hukum sebagai upaya dalam mengatasi permasalahan tersebut dan upaya-upaya preventif yang dilakukan, serta akan dianalisa efektivitas dari upaya-upaya yang telah ada tersebut dalam mengatasi permasalahan dalam penelitian ini. Metode pendekatan yang dipakai dalam penelitian ini adalah yuridis kualitatif, yakni dengan didasarkan pada data sekunder yang berupa bahan hukum primer, sekunder, dan tersier. Penelitian ini akan melakukan kajian kepustakaan serta pengolahan data secara kualitatif. Data-data yang terkumpul akan dianalisa dengan menggunakan pendekatan hukum, khususnya hukum administrasi dan hukum pidana, yang pada akhirnya menemukan pembenaran atas tindakan aparat kepolisian dalam melakukan penindakan bagi pengguna roda dua dengan knalpot non-standar, dimana hal tersebut merupakan kewenangannya meskipun ada kekurangan dalam hal teknis karena tidak dimilikinya alat pengukur kebisingan suara pada saat melakukan pemeriksaan kendaran di jalan raya..

\section{HASIL DAN PEMBAHASAN}

\section{A. Ketentuan Hukum Pemakaian Knalpot non- standar pada Kendaraan Roda 2 (dua) di Indonesia}

Pengaturan pemakaian knalpot non-standar pada kendaraan bermotor roda 2 terdapat dalam peraturan perundang-undangan seperti Undang-Undang No. 22 tahun 2009 tentang Lalu Lintas dan Angkutan Jalan dan Peraturan Menteri Lingkungan Hidup No. 7 Tahun 2009 tentang Ambang Batas Kebisingan Kendaraan Bermotor Tipe Baru. Dari hasil analisis setiap peraturan perundangundangan ini perihal pengaturan terhadap pengguna knalpot non-standar di jalan raya, aturan perundangundangan Undang-Undang No. 22 tahun 2009 tentang Lalu Lintas dan Angkutan Jalan ini hanya sebatas aturan tertulis yang pada pelaksanaannya tidak ada kejelasan atas dasar pelanggaran bagi pengguna knalpot non-standar. Ambang batas kebisingan kendaraan bermotor tertulis dalam Peraturan Menteri Lingkungan Hidup No. 7 Tahun 2009, tetapi pada pelaksanaannya dilapangan para penegak hukum melakukan penindakan atas dasar bentuk dari knalpot, bukan dari hasil suara yang dikeluarkan dari knalpot. Dalam penindakannya penegak hukum dalam hal ini pihak kepolisian dan dishub dalam melaksanakan penindakan dalam hal pengujian kebisingan, tidak pernah menguji berapa tingkat kebisingan yang dihasilkan dan penegak hukum tidak memiliki alat untuk mengukur tingkat kebisingan yang dihasilkan dari knalpot pengguna kendaraan bermotor di jalan raya.

Pengujian perihal penindakan telah di atur dalam Peraturan Menteri Lingkungan Hidup No. 7 Tahun 2009 tentang Ambang Batas Kebisingan Kendaraan Bermotor Tipe Baru, untuk kendaraan bermotor dengan cc di bawah 80cc maksimal $77 \mathrm{~dB}$, kendaraan bermotor 80cc hingga $175 \mathrm{cc}$ maksimal $80 \mathrm{~dB}$, dan kendaraan bermotor dengan $175 \mathrm{cc}$ lebih maksimal $83 \mathrm{~dB}$.

\section{B. Efektivitas Penerapan Sanksi terhadap Pemilik Kendaraan Roda 2 (dua) yang Memakai Knalpot non-standar}

Undang-undang Nomor 22 Tahun 2009 Tentang Lalu Lintas dan Angkutan Jalan mengatur tentang pengemudi sepeda motor yang tidak memenuhi persyaratan teknis laik jalan yang meliputi kaca, knalpot, lampu penunjuk arah. Ancaman yang termuat dalam Pasal 106 (3) jo Pasal 48 (2) dan (3) baik pidana maupun denda bagi pelanggar. Upaya pencegahan untuk menanggulangi terjadinya pelanggaran lalu lintas dengan cara melakukan sosialisasi mengenai penggunaan knalpot standar atau sosialisasi pengunaan knalpot non-standar yang legal itu bagaimana, serta diperlukannya kajian lebih mendalam mengenai manfaat ataupun kerugian yang akan muncul dari penggunaan knalpot yang tidak standar atau dampak terhadap industri knalpot non-standar yang sudah berjalan. Salah satu upaya preventif yaitu dengan memberikan pendidikan dan penyuluhan kepada anggota masyarakat serta, melakukan himbauan-himbauan terkait ketentuan peraturan perundang-undangan dimaksud, sehingga dapat meminimalisir langkah-langkah represif dngan melakukan razia atau penilangan terhadap pengguna kendaraan roda dua dengan knalpot non-standar.

Berdasarkan hasil penelitian dapat diketahui bahwa faktor-faktor yang menyebabkan masyarakat tidak menggunakan Knalpot Standar dalam mengendarai kendaraan bermotor di Kota Bandung, Cimahi, Kabupaten Bandung antara lain: mengikuti modifikasi model kendaraan, tidak mengetahui bila hal tersebut melanggar hukum, pengaruh teman, kurang nyaring bunyi knalpot dari pabrikan serta kurang menariknya bentuk yang dipasang dari pabrik. Selain itu, pihak pengguna kendaraan tidak seluruhnya secara sengaja melakukan modifikasi dengan tujuan negatif. Biasanya pengguna memodifikasi dengan tujuan demi keselamatan si pengguna sendiri.

Berdasarkan Kegiatan Penindakan selama tahun 2016, 2017 dan 2018 (Januari s/d Agustus 2018) tersebut diperoleh hasil sebanyak 19.153 knalpot bising/ nonstandar dan diamankan di Sat Lantas Polrestabes Bandung dan telah di buat Tugu Knalpot yang berada di halaman depan Polrestabes Bandung, dengan hasil sebagai berikut: 
Gambar 1. Penindakan knalpot

\begin{tabular}{|c|c|c|c|c|c|c|}
\hline \multirow[b]{2}{*}{ NO } & \multirow[b]{2}{*}{ KESATUAN } & \multicolumn{4}{|c|}{ PENINDAKAN KNALPOT } & \multirow[b]{2}{*}{ JML TOTAL } \\
\hline & & 2016 & 2017 & JML & $\begin{array}{c}2018 \\
(\mathrm{JAN}-\mathrm{APR})\end{array}$ & \\
\hline 1 & 2 & 3 & 4 & 5 & 6 & 7 \\
\hline 1 & SAT LANTAS POLRESTABES BDG & 7.915 & 6.803 & 14.718 & 1.390 & 16.108 \\
\hline 2 & SUKAJADI & - & 83 & 83 & 23 & 106 \\
\hline 3 & SUKASARI & - & 96 & 96 & 15 & 111 \\
\hline 4 & CICENDO & - & 88 & 88 & 20 & 108 \\
\hline 5 & ANDIR & - & 79 & 79 & 20 & 99 \\
\hline 6 & ASTANA ANYAR & - & 96 & 96 & 17 & 123 \\
\hline 7 & BJL. KALER & - & 99 & 99 & 19 & 118 \\
\hline 8 & BJL. KIDUL & - & 105 & 105 & 14 & 119 \\
\hline 9 & BBK. CIPARAY & - & 87 & 87 & 10 & 97 \\
\hline 10 & BDG KULON & - & 107 & 107 & 15 & 122 \\
\hline 11 & CIDADAP & - & 110 & 110 & 6 & 106 \\
\hline 12 & COBLONG & - & 56 & 56 & 5 & 61 \\
\hline 13 & BAWET & - & 40 & 40 & 18 & 58 \\
\hline 14 & SUMUR BDG & - & 67 & 67 & 7 & 74 \\
\hline 15 & REGOL & - & 110 & 110 & 9 & 119 \\
\hline 16 & LENGKONG & - & 100 & 100 & 12 & 112 \\
\hline 17 & KIRCON & - & 104 & 104 & 7 & 111 \\
\hline 18 & CIB. KALER & - & 93 & 93 & 4 & 97 \\
\hline 19 & CIB. KIDUL & - & 92 & 92 & 7 & 99 \\
\hline 20 & ANTAPANI & - & 106 & 106 & 9 & 115 \\
\hline 21 & ARCAMANIK & - & 89 & 89 & 26 & 115 \\
\hline 22 & PANYILEUKAN & - & 147 & 147 & 11 & 158 \\
\hline 23 & BDG KIDUL & - & 90 & 90 & 13 & 103 \\
\hline 24 & BUAHBATU & - & 108 & 108 & 35 & 143 \\
\hline 25 & RANCASARI & - & 119 & 119 & 18 & 137 \\
\hline 26 & UJUNGBERUNG & - & 150 & 150 & 39 & 189 \\
\hline 27 & GEDEBAGE & - & 95 & 95 & 34 & 129 \\
\hline \multirow[t]{2}{*}{28} & CINAMBO & - & 101 & 101 & 15 & 119 \\
\hline & JUMLAH TOTAL & 7.915 & 9.420 & 17.335 & 1.818 & 19.153 \\
\hline
\end{tabular}

Sumber: Sat Polantas Polrestabes Kota Bandung 2018

\section{SIMPULAN}

Ketentuan yang mengatur mengenai penggunaan knalpot non-standar dalam Undang-Undang Nomor 22 Tahun 2009 belum dapat dikatakan berlaku secara efektif. Hal ini dikarenakan masih banyak masyarakat yang belum sepenuhnya memahami ketentuan ini. Pengaturan mengenai penggunaan knalpot non-standar dalam Undang-Undang Nomor 22 Tahun 2009 belum mampu mempolakan disiplin masyarakat dalam berlalu lintas di jalan, sebab tidak adanya peraturan yang sifatnya sinergis yang mendasari tindakan pengukuran kebisingan di jalan raya dan tidak adanya alat uji dilapangan yang menjadi penghambat penegak hukum dalam melakukan pemeriksaan dan penindakan kendaraan dengan paripurna, sehingga tindakan aparat kepolisian tersebut dianggap oleh masyarakat sebagai hal yang negatif karena mendasarkan tindakannya pada naluri dan ukuran subjektifitas dari aparat penegak hukum bukan berdasarkan pada hasil pengujian dari alat yang terstandarisasi dan diperuntukan untuk mengukur kebisingan suara.

\section{DAFTAR PUSTAKA}

Laporan Hasil Pelaksanaan Penindakan Terhadap Ranmor Yang Menggunakan Knalpot Bising / Bukan Standar, Kepolisian Negara Republik Indonesia Daerah Jawa Barat Resor Kota Besar Bandung.

Penjelasan berdasarkan wawancara dengan IPTU Rustandi kepala Satuan Lalu Lintas Unit Turjawali Polrestabes Kota Bandung mengenai memodifikasi kendaraan bermotor, Senin 04 Juni 2018 Pukul $13.00-14.30$.

Soemitro, Ronny Hanitijo.(1988). Metodologi Penelitian Hukum dan Jurimetri, Jakarta: Ghalia Indonesia. 
Sudikno Mertokusumo, (1999), Mengenal Hukum, Yogyakarta : Liberty.

Undang-Undang Nomor 22 Tahun 2009 Tentang Lalu Lintas dan Angkutan Jalan.

Peraturan Menteri Lingkungan Hidup No.7 Tahun 2009.

https:/jabar.bps.go.id/statictable/2018/03/19/416/jumlahkendaraan-bermotor-umum-dan-bukan-umumuntuk-bpkb-menurut-cabang-pelayanan-di-jawabarat-2016.html. https://bandung.bisnis.com/read/20181002/549/1114194/ pertumbuhan-kendaraan-di-bandung-11-pertahun.

https://jabar.bps.go.id/statictable/2018/03/19/396/ jumlah-kecelakaan-lalu-lintas-menurut-polresdan-kendaraan-yang-terlibat-di-provinsi-jawabarat-2016.html. 